\title{
Luteimonas composti sp. nov., a moderately thermophilic bacterium isolated from food waste
}

\author{
Correspondence \\ Peter Kämpfer \\ peter.kaempfer@agrar. \\ uni-giessen.de
}

\author{
Chiu-Chung Young, ${ }^{1}$ Peter Kämpfer, ${ }^{2}$ Wen-Ming Chen, ${ }^{3}$ Wen-Shao Yen, ${ }^{1}$ \\ A. B. Arun, ${ }^{1}$ Wei-An Lai, ${ }^{1}$ Fo-Ting Shen, ${ }^{1}$ P. D. Rekha, ${ }^{1}$ Kuan-Yin Lin ${ }^{3}$ \\ and Jui-Hsing $\mathrm{Chou}^{1}$
}

\author{
${ }^{1}$ College of Agriculture and Natural Resources, Department of Soil \& Environmental Sciences, \\ National Chung Hsing University, Taichung 402, Taiwan, ROC \\ ${ }^{2}$ Institut für Angewandte Mikrobiologie, Universität Giessen, Giessen, Germany \\ ${ }^{3}$ Laboratory of Microbiology, Department of Seafood Science, National Kaohsiung Marine \\ University, Kaohsiung City 811, Taiwan, ROC
}

\begin{abstract}
A yellow-pigmented, Gram-negative, rod-shaped bacterium (strain CC-YY $255^{\top}$ ) was isolated from compost generated from food waste collected from Kinmen County, Taiwan. 16S rRNA gene sequence analysis indicated that the strain formed a monophyletic branch at the periphery of the evolutionary radiation occupied by the genus Luteimonas; its closest neighbour was the type strain of Luteimonas mephitis ( $94.4 \%$ sequence similarity). The isolate was distinguished from Luteimonas mephitis on the basis of several phenotypic properties. The organism utilized glucose, maltose, gentiobiose, melibiose and turanose and only a few organic acids (acetate, propionate) and amino acids (L-alanyl glycine, glycyl L-aspartic acid and glycyl L-glutamic acid) as substrates. The fatty acid profile was slightly different from that reported for Luteimonas mephitis. It is evident from the genotypic, chemotaxonomic and physiological data presented that strain CC-YY $255^{\top}$ represents a novel species of the genus Luteimonas, for which the name Luteimonas composti sp. nov. is proposed. The type strain is CC-YY $255^{\top}\left(=\right.$ CCUG $53595^{\top}=\mathrm{CIP}^{\top} 109311^{\top}=\mathrm{BCRC}$ $\left.17598^{\top}\right)$.
\end{abstract}

During the characterization of micro-organisms from compost generated from food waste of Kinmen County located in Taiwan, strain CC-YY $255^{\mathrm{T}}$ was isolated and maintained on nutrient agar after incubating at $32{ }^{\circ} \mathrm{C}$ for 3 days. Subcultivation was performed on nutrient agar (Oxoid) at $30^{\circ} \mathrm{C}$ for between 48 and $72 \mathrm{~h}$. On this medium, strain CC-YY $255^{\mathrm{T}}$ was able to grow at $20-45^{\circ} \mathrm{C}$, but not at 10 or $50^{\circ} \mathrm{C}$. The organism was able to grow on nutrient agar and tryptone soy (TS) agar (Oxoid). Gram-staining was performed as described by Gerhardt et al. (1994). Poly- $\beta$ hydroxybutyrate granule accumulation was observed by light microscopy after staining cells with Sudan black. Phenotypic characteristics, biochemical tests, carbon source utilization (Biolog GN2) and API ZYM, API 20E and API 20NE (all bioMérieux) profiles were investigated. Additionally, antibiotic susceptibility testing was carried out by using ATB STAPH 5 strips (bioMérieux) according to the manufacturer's recommendations. Tests for fluorescence were made after plating on to King's B medium for $48 \mathrm{~h}$. For

The GenBank/EMBL/DDBJ accession number for the $16 \mathrm{~S}$ rRNA gene sequence of strain CC-YY255 ${ }^{\top}$ is DO846687.

Detailed results for strain CC-YY255 ${ }^{\top}$ with the Biolog GN2 system are available as supplementary material in IJSEM Online.
$\mathrm{G}+\mathrm{C}$ content determinations, DNA was prepared and degraded enzymically into nucleosides as described by Mesbah et al. (1989). The nucleoside mixture obtained was then separated by HPLC. The G+C content of strain CC-YY255 ${ }^{\mathrm{T}}$ was $68.1 \mathrm{~mol} \%$.

Cell morphology was observed under a Zeiss light microscope at $\times 1000$ magnification, using cells that had been grown for 3 days at $30^{\circ} \mathrm{C}$ on nutrient agar (Oxoid). Details of cell morphology are given in the species description below. The $\mathrm{pH}$ range for growth was determined by measuring the $\mathrm{OD}_{595}$ of the culture grown in nutrient broth (Difco), which was adjusted prior to sterilization to various $\mathrm{pH}$ values ( $\mathrm{pH} 3-11$ at intervals of $0.5 \mathrm{pH}$ units) by using appropriate biological buffers (Chung et al., 1995). Growth at various temperatures $\left(15-70{ }^{\circ} \mathrm{C}\right)$ was measured on nutrient broth. Growth under anaerobic conditions was determined after incubation in an Oxoid AnaeroGen system on nutrient medium. Growth was recorded by measuring the $\mathrm{OD}_{595}$ of the culture with respect to time.

The 16S rRNA gene was analysed as described previously (Young et al., 2005). Analysis of the sequence data was performed by using the software package MEGA, version 2.1 (Kumar et al., 2001), after multiple alignments of the 
data by CLUSTAL_X (Thompson et al., 1997). A distance matrix method (distance options according to the Kimura two-parameter model), including clustering by neighbourjoining (Fig. 1), and a discrete character-based maximumparsimony method were used. In each case bootstrap values were calculated based on 1000 replications. The $16 \mathrm{~S}$ rRNA gene sequence of strain CC-YY $255^{\mathrm{T}}$ was a continuous stretch of $1501 \mathrm{bp}$. Sequence similarity calculations (over $1355 \mathrm{bp}$ ) indicated that strain CC-YY $255^{\mathrm{T}}$ was related most closely to Luteimonas mephitis DSM $12574^{\mathrm{T}}$ (94.4\% 16S rRNA gene sequence similarity), Lysobacter antibioticus DSM $2044^{\mathrm{T}}$ (94.2\%), Stenotrophomonas rhizophila DSM $14405^{\mathrm{T}}$ (94.0\%) (GenBank accession no. AJ293463), Thermomonas brevis DSM $15422^{\mathrm{T}}$ (93.6\%) (GenBank accession no. AJ519985) and Xanthomonas oryzae LMG $5047^{\mathrm{T}}$ (93.8\%) (GenBank accession no. X95921). Lower sequence similarities $(<93.5 \%)$ were found with representative members of the other genera shown in Fig. 1 .

Fatty acid methyl esters were prepared, separated and identified according to the instructions of the Microbial Identification System (MIDI; Microbial ID). Luteimonas mephitis DSM $12574^{\mathrm{T}}$ was tested for comparative purposes. The fatty acid profile of strain CC-YY255 ${ }^{\mathrm{T}}$ (Table 1) was similar to that given for Luteimonas mephitis (Finkmann et al., 2000), but showed some significant differences (Table 1).

Isoprenoid quinone analysis was performed by reversedphase TLC according to Collins (1985). Analysis of quinones revealed a spot that corresponded to ubiquinone-8 (Q-8). This quinone system is a characteristic feature of the Betaproteobacteria (Collins \& Jones, 1981; Yokota et al., 1992; Busse et al., 2002).

Results of the physiological characterization tests are given in the species description below and in Table 2. Luteimonas mephitis DSM $12574^{\mathrm{T}}$ was tested for comparison. Strain
$\mathrm{CC}-\mathrm{YY} 255^{\mathrm{T}}$ was non-fluorescent and was capable of producing acid from various carbohydrates. However, carbon substrate utilization tests with organic acids as substrates showed few positive results. In API 20E tests, strain CCYY $255^{\mathrm{T}}$ was positive for $\beta$-galactosidase and gelatinase and oxidation of glucose, melibiose and arabinose; in API 20NE tests, strain CC-YY $255^{\mathrm{T}}$ was positive for the reduction of nitrate to nitrite, aesculin hydrolysis, gelatinase, $\beta$-glucosidase and assimilation of glucose, arabinose, $\mathrm{N}$-acetylglucosamine and maltose. In API ZYM enzyme profiling, $\mathrm{CC}-\mathrm{YY} 255^{\mathrm{T}}$ was positive for alkaline and acid phosphatase, butyrate esterase, caprylate esterase (C8), leucine arylamidase, valine arylamidase, $\alpha$-chymotrypsin, naphthol-AS-BIphosphohydrolase, $\alpha$-glucosidase and $N$-acetyl- $\beta$-glucosaminidase.

Although strain CC-YY255 ${ }^{\mathrm{T}}$ showed low $16 \mathrm{~S}$ rRNA gene sequence similarities $(<95 \%)$ to members of all other phylogenetically related genera (Lysobacter, Thermomonas etc.), including Luteimonas, a clear phenotypic differentiation from Luteimonas mephitis that might justify the proposal of a new genus was not found. We therefore consider that strain CC-YY $255^{\mathrm{T}}$ represents a second, novel member of the genus Luteimonas, for which the name Luteimonas composti sp. nov. is proposed.

\section{Description of Luteimonas composti sp. nov.}

Luteimonas composti (com.pos'ti. N.L. gen. n. composti of compost).

Cells are Gram-negative, aerobic, non-motile short rods, $0.5 \mu \mathrm{m}$ in length and about $1.0-1.5 \mu \mathrm{m}$ in width. Good growth occurs after $48 \mathrm{~h}$ incubation on TS agar and nutrient agar at $30^{\circ} \mathrm{C}$. Colonies on complex standard media at $37^{\circ} \mathrm{C}$ are yellow, circular, smooth, shiny and convex with an entire edge, $1.0-2.0 \mathrm{~mm}$ in diameter and non-fluorescent. The optimal temperature for growth is $30{ }^{\circ} \mathrm{C}$. Growth occurs at 20 and $45^{\circ} \mathrm{C}$, but not at $50^{\circ} \mathrm{C}$. The optimal $\mathrm{pH}$ for growth is

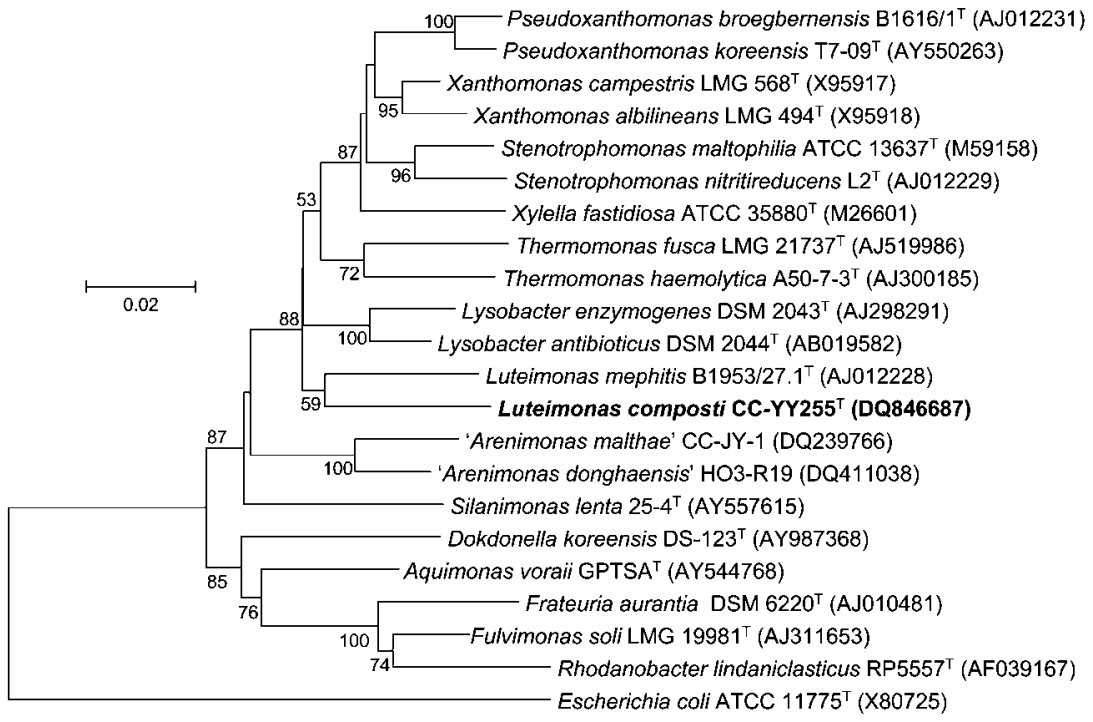

Fig. 1. Phylogenetic analysis based on $16 \mathrm{~S}$ rRNA gene sequences available from the EMBL database (accession numbers are given in parentheses) constructed after multiple alignments of the data by using CLUSTAL_X (Thompson et al., 1997). Distances (distance options according to the Kimura two-parameter model) and clustering with the neighbour-joining method were determined by using the software package MEGA, version 2.1 (Kumar et al., 2001). Bootstrap values based on 1000 replications are listed as percentages at branch points. Bar, 0.02 substitutions per nucleotide position. 
Table 1. Fatty acid compositions (\%) of strain CC-YY $255^{\top}$ and Luteimonas mephitis

Data for individual type strains are from this study. Comparative data for 15 strains of Luteimonas mephitis are from Finkmann et al. (2000). The type strains were grown on trypticase soy broth agar at $28{ }^{\circ} \mathrm{C}$ for $48 \mathrm{~h}$ prior to fatty acid analysis. For unsaturated fatty acids, the position of the double bond is located by counting from the methyl $(\omega)$ end of the carbon chain. cis isomers are indicated by the suffix $c$.

\begin{tabular}{|c|c|c|c|}
\hline \multirow[t]{2}{*}{ Fatty acid } & \multirow{2}{*}{$\begin{array}{c}\text { Strain } \\
\text { CC-YY255 }\end{array}$} & \multicolumn{2}{|c|}{ Luteimonas mephitis } \\
\hline & & DSM $12574^{\mathrm{T}}$ & 15 strains \\
\hline \multicolumn{4}{|c|}{ Saturated (straight-chain): } \\
\hline $\mathrm{C}_{10: 0}$ & & 0.1 & \\
\hline $\mathrm{C}_{14: 0}$ & & 0.7 & $0.3-0.5$ \\
\hline $\mathrm{C}_{16: 0}$ & 4.7 & 1.6 & $0.9-2.1$ \\
\hline \multicolumn{4}{|l|}{ Saturated (branched): } \\
\hline iso- $\mathrm{C}_{10: 0}$ & 0.4 & 0.1 & \\
\hline iso- $\mathrm{C}_{11: 0}$ & 6.5 & 5.2 & $3.8-5.1$ \\
\hline anteiso- $\mathrm{C}_{11: 0}$ & 0.3 & 0.2 & $0.2-0.2$ \\
\hline iso- $\mathrm{C}_{13: 0}$ & & 0.5 & $0.2-0.6$ \\
\hline iso- $\mathrm{C}_{14: 0}$ & 1.9 & 1.5 & $0.5-1.3$ \\
\hline iso- $\mathrm{C}_{15: 1} 7$ & 1.9 & 3.0 & $0.8-4.1$ \\
\hline iso- $\mathrm{C}_{15: 0}$ & 25.5 & 47.4 & $38.1-57.3$ \\
\hline anteiso- $\mathrm{C}_{15: 0}$ & 2.7 & 3.0 & $2.0-3.8$ \\
\hline iso- $\mathrm{C}_{16: 0}$ & 13.8 & 5.6 & $1.6-10.6$ \\
\hline iso- $\mathrm{C}_{17: 0}$ & 5.5 & 5.5 & $3.7-11.0$ \\
\hline \multicolumn{4}{|l|}{ Unsaturated: } \\
\hline $\mathrm{C}_{16: 1} \omega 9 c$ & & & $0.7-1.2$ \\
\hline iso- $\mathrm{C}_{17: 1} \omega 9 c$ & 25.5 & 18.7 & $18.2-26.4$ \\
\hline \multicolumn{4}{|l|}{ Hydroxy: } \\
\hline iso- $\mathrm{C}_{11: 0} 3-\mathrm{OH}$ & 5.5 & 5.3 & $2.0-2.7$ \\
\hline Summed feature $3^{*}$ & 5.5 & 0.9 & \\
\hline \multicolumn{4}{|l|}{ Cyclopropane acids: } \\
\hline $\mathrm{C}_{17: 0}$ cyclo & & 0.2 & \\
\hline
\end{tabular}

${ }^{*}$ Summed features are groups of two or three fatty acids that cannot be separated by GLC with the MIDI system. Summed feature 3 comprised $\mathrm{C}_{16: 1} \omega 7 c$ and/or iso- $\mathrm{C}_{15: 0} 2-\mathrm{OH}$.

7.0; growth occurs at $\mathrm{pH} 7$ and 10, but not at $\mathrm{pH} 6.0$ or 11 . Growth occurs in the presence of $0-6 \%(\mathrm{w} / \mathrm{v}) \mathrm{NaCl}$; optimal growth occurs in the presence of $0-0.5 \%(\mathrm{w} / \mathrm{v}) \mathrm{NaCl}$. No anaerobic growth on plain NA or TSA supplemented with nitrate. Poly- $\beta$-hydroxybutyrate granule accumulation is observed via microscopy. Shows aerobic metabolism. Positive for oxidase, catalase, gelatinase and aesculin. Nitrate is reduced to nitrite. Ubiquinone Q-8 is the predominant quinone. The fatty acid profile of strain $\mathrm{CC}-\mathrm{YY} 255^{\mathrm{T}}$ is detailed in Table 1 . The following carbon sources are utilized (positive with the Biolog GN2 system): gentiobiose, $\alpha$-D-glucose, maltose, D-melibiose, turanose, pyruvic acid methyl ester, L-alaninamide, L-alanyl glycine, glycyl L-aspartic acid, glycyl L-glutamic acid and inosine. The remaining substrates of the Biolog GN2 system are not utilized (see Supplementary Table S1). Positive reactions
Table 2. Selected physiological characteristics that separate strain CC-YY $255^{\top}$ from Luteimonas mephitis

Data are from this study unless indicated. W, Weak.

\begin{tabular}{|lcc|}
\hline Characteristic & $\begin{array}{c}\text { Strain } \\
\text { CC-YY255 }^{\mathrm{T}}\end{array}$ & $\begin{array}{c}\text { Luteimonas mephitis } \\
\text { DSM } \text { 12574 }^{\mathrm{T}}\end{array}$ \\
\hline Growth at $37^{\circ} \mathrm{C}$ & + & - \\
Nitrate reduction & + & $-*$ \\
Utilization of: & & $\mathrm{W}$ \\
D-Glucose & + & - \\
D-Galactose & + & + \\
D-Gluconate & - & - \\
Acetate & + & - \\
Propionate & + & - \\
DL-3-Hydroxybutyrate & + & \\
\hline
\end{tabular}

${ }^{\star}$ Data from Finkmann et al. (2000).

(API 20E and 20NE systems) are seen for $\beta$-galactosidase, gelatinase, oxidation of glucose, melibiose and arabinose, reduction of nitrate to nitrite, $\beta$-glucosidase, aesculin hydrolysis, glucose assimilation, arabinose assimilation, $\mathrm{N}$-acetylglucosamine and maltose assimilation, but negative reactions for arginine dihydrolase, lysine decarboxylase, ornithine decarboxylase, citrate utilization, $\mathrm{H}_{2} \mathrm{~S}$ production, urease, tryptophan deaminase, indole production, acetoin, oxidation of mannitol, inositol, sorbitol, rhamnose, sucrose and amygdalin, reduction of nitrates to nitrogen, glucose fermentation, urease and assimilation of mannose, mannitol, potassium gluconate, capric acid, adipic acid, malate, trisodium citrate and phenylacetic acid. Positive in API ZYM enzyme reactions for alkaline phosphatase, butyrate esterase (C4), caprylate esterase (C8), leucine arylamidase, valine arylamidase, $\alpha$-chymotrypsin, acid phosphatase, naphthol-AS-B-1-phosphohydrolase, $\beta$-galactosidase, $\alpha$ glucosidase, $\beta$-glucosidase and $N$-acetyl- $\beta$-glucosaminidase, but negative for myristate lipase (C14), cystine arylamidase, trypsin, $\alpha$-galactosidase, $\beta$-glucuronidase, $\alpha$-mannosidase and $\alpha$-fucosidase. Sensitive to gentamicin, tetracyclines, minocycline, nor/quinolones $2 \mathrm{G}$ and levofloxacin, but resistant to penicillin, cotrimoxazole, erythromycin, clindamycin, teicoplanin, nitrofurantonin, quinupristine-dalfo, coag-oxacillin and oxacillin. Intermediate resistance is observed for vancomycin, rifampicin and fusidic acid. Further physiological characteristics are given in Table 1. The DNA G + C content is $68.1 \%$.

The type strain, CC-YY $255^{\mathrm{T}} \quad\left(=\mathrm{CCUG} 53595^{\mathrm{T}}=\mathrm{CIP}\right.$ $109311^{\mathrm{T}}=$ BCRC $\left.17598^{\mathrm{T}}\right)$, was isolated from compost generated from food waste.

\section{Acknowledgements}

This research work was supported by a grant from the Ministry of Economic Affairs and National Science Council, Taiwan, ROC. We thank W. S. Huang for technical assistance. We thank A. Lipski for kindly providing Luteimonas mephitis DSM $12574^{\mathrm{T}}$. 


\section{References}

Busse, H.-J., Kämpfer, P., Moore, E. R. B., Nuutinen, J., Tsitko, I. V., Denner, E. B. M., Vauterin, L., Valens, M., Rossello-Mora, R. \& Salkinoja-Salonen, M. S. (2002). Thermomonas haemolytica gen. nov., sp. nov., a gammaproteobacterium from kaolin slurry. Int J Syst Evol Microbiol 52, 473-483.

Chung, Y. C., Kobayashi, T., Kanai, H., Akiba, T. \& Kudo, T. (1995). Purification and properties of extracellular amylase from the hyperthermophilic archeon Thermococcus profundus DT5432. Appl Environ Microbiol 61, 1502-1506.

Collins, M. D. (1985). Isoprenoid quinone analysis in bacterial classification and identification. In Chemical Methods in Bacterial Systematics, pp. 267-288. Edited by M. Goodfellow \& A. G. O'Donnell. London: Academic Press.

Collins, M. D. \& Jones, D. (1981). Distribution of isoprenoid quinone structural types in bacteria and their taxonomic implication. Microbiol Rev 45, 316-354.

Finkmann, W., Altendorf, K., Stackebrandt, E. \& Lipski, A. (2000). Characterization of $\mathrm{N}_{2} \mathrm{O}$-producing Xanthomonas-like isolates from biofilters as Stenotrophomonas nitritireducens sp. nov., Luteimonas mephitis gen. nov., sp. nov. and Pseudoxanthomonas broegbernensis gen. nov., sp. nov. Int J Syst Evol Microbiol 50, 273-282.
Gerhardt, P., Murray, R. G. E., Wood, W. A. \& Krieg, N. R. (editors) (1994). Methods for General and Molecular Bacteriology. Washington, DC: American Society for Microbiology.

Kumar, S., Tamura, K., Jakobsen, I.-B. \& Nei, M. (2001). MEGA2: molecular evolutionary genetics analysis software. Bioinformatics 17, 1244-1245.

Mesbah, M., Premachandran, U. \& Whitman, W. B. (1989). Precise measurement of the $\mathrm{G}+\mathrm{C}$ content of deoxyribonucleic acid by high-performance liquid chromatography. Int J Syst Bacteriol 39, 159-167.

Thompson, J. D., Gibson, T. J., Plewniak, F., Jeanmougin, F. \& Higgins, D. G. (1997). The CLUSTAL_X windows interface: flexible strategies for multiple sequence alignment aided by quality analysis tools. Nucleic Acids Res 25, 4876-4882.

Yokota, A., Akagawa-Matsushita, M., Hiraishi, A., Katayama, Y., Urakami, T. \& Yamasato, K. (1992). Distribution of quinone systems in microorganisms: Gram-negative Eubacteria. Bull Jpn Fed Cult Coll 8, 136-171.

Young, C.-C., Kämpfer, P., Shen, F.-T., Lai, W.-A. \& Arun, A. B. (2005). Chryseobacterium formosense sp. nov., isolated from the rhizosphere of Lactuca sativa L. (garden lettuce). Int J Syst Evol Microbiol 55, 423-426. 